\title{
Identification of a 467 bp Promoter of Maize Phosphatidylinositol Synthase Gene (ZmPIS) Which Confers High-Level Gene Expression and Salinity or Osmotic Stress Inducibility in Transgenic Tobacco
}

OPEN ACCESS

Edited by:

Sagadevan G. Mundree, Queensland University of Technology,

Australia

Reviewed by:

Andrzej Miroslaw Pacak, Adam Mickiewicz University, Poland

Taras P. Pasternak, Albert-Ludwigs-Universität Freiburg,

Germany

Upinder S. Gill,

The Samuel Roberts Noble Foundation, USA

*Correspondence: Kunpeng $\mathrm{Li}$

likp@sdu.edu.cn

tThese authors have contributed equally to this work.

Specialty section: This article was submitted to

Plant Biotechnology,

a section of the journal

Frontiers in Plant Science

Received: 30 October 2015 Accepted: 11 January 2016

Published: 01 February 2016

Citation:

Zhang H, Hou J, Jiang P, Qi S, Xu C, He Q, Ding Z, Wang Z, Zhang K and Li K (2016) Identification of a $467 \mathrm{bp}$ Promoter of Maize Phosphatidylinositol Synthase Gene (ZmPIS) Which Confers High-Level

Gene Expression and Salinity or

Osmotic Stress Inducibility in Transgenic Tobacco

Front. Plant Sci. 7:42.

doi: 10.3389/fpls.2016.00042
Hongli Zhang ${ }^{1+}$, Jiajia Hou ${ }^{1+}$, Pingping Jiang ${ }^{1}$, Shoumei Qi ${ }^{1}$, Changzheng $X u^{2}$, Qiuxia He ${ }^{3}$, Zhaohua Ding ${ }^{4}$, Zhiwu Wang ${ }^{4}$, Kewei Zhang ${ }^{1}$ and Kunpeng Li ${ }^{1 *}$

${ }^{1}$ Key Laboratory of Plant Cell Engineering and Germplasm Innovation, Ministry of Education, School of Life Science, Shandong University, Jinan, China, ${ }^{2}$ Research Center of Bioenergy and Bioremediation, College of Resources and Environment, Southwest University, Chongqing, China, ${ }^{3}$ Biology Institute of Shandong Academy of Sciences, Jinan, China, ${ }^{4}$ Maize Institute of Shandong Academy of Agricultural Sciences, Jinan, China

Salinity and drought often affect plant growth and crop yields. Cloning and identification of salinity and drought stress inducible promoters is of great significance for their use in the genetic improvement of crop resistance. Previous studies showed that phosphatidylinositol synthase is involved in plant salinity and drought stress responses but its promoter has not been characterized by far. In the study, the promoter ( $p Z m P I S$, $1834 \mathrm{bp}$ upstream region of the translation initiation site) was isolated from maize genome. To functionally validate the promoter, eight $5^{\prime}$ deletion fragments of $p Z m P I S$ in different lengths were fused to GUS to produce pZmPIS::GUS constructs and transformed into tobacco, namely PZ1-PZ8. The transcription activity and expression pattern obviously changed when the promoter was truncated. Previous studies have demonstrated that $\mathrm{NaCl}$ and $\mathrm{PEG}$ treatments are usually used to simulate salinity and drought treatments. The results showed that PZ1-PZ7 can respond well upon $\mathrm{NaCl}$ and PEG treatments, while PZ8 not. PZ7 (467 bp) displayed the highest transcription activity in all tissues of transgenic tobacco amongst $5^{\prime}$ deleted promoter fragments, which corresponds to about 20 and $50 \%$ of CaMV35S under normal and $\mathrm{NaCl}$ or PEG treatment, respectively. This implied that $\mathrm{PZ7}$ is the core region of $p Z m P / S$ which confers high-level gene expression and $\mathrm{NaCl}$ or PEG inducible nature. The $113 \mathrm{bp}$ segment between PZ7 and PZ8 ( -467 to -355 bp) was considered as the key sequence for ZmPIS responding to $\mathrm{NaCl}$ or PEG treatment. GUS transient assay in tobacco leaves showed that this segment was sufficient for the $\mathrm{NaCl}$ or PEG stress response. Bioinformatic analysis revealed that the 113 bp sequence may contain new elements that are crucial for $Z m P I S$ response to $\mathrm{NaCl}$ or PEG stress. These results promote our understanding on transcriptional regulation mechanism of ZmPIS and the characterized PZ7 promoter fragment would be an ideal candidate for the overexpression of drought and salinity responsive gene to improve crop resistance.

Keywords: abiotic stress, GUS analysis, inducible promoter, Nicotiana benthamiana, Zea mays L., ZmPIS 


\section{INTRODUCTION}

Salinity and drought interferes plant growth as it causes osmotic stress and ion toxicity (Golldack et al., 2014). Global crop production is often affected by salinity or drought stress and the problem becomes increasingly serious (Munns and Tester, 2008; Tester and Langridge, 2010; Agarwal et al., 2013). Genetic improvement in crops by transgenic technology is considered as an effective way of solving this problem. An appropriate promoter that enables transgene expression at desired levels plays crucial roles in efficient production of transgenic plants (Potenza et al., 2004; Han et al., 2015; Tao et al., 2015). Isolation of various promoters and characterization of their expression patterns are necessary for transgenic breeding.

To date, promoter resources for crop genetic improvement are still quite limited. Constitutive promoters, such as CaMV35S promoter and maize ubiquitin promoter, are currently in use (Odell et al., 1985; Cornejo et al., 1993). CaMV35S promoter drives high-level gene expression in dicot plants, while maize ubiquitin promoter is more capable of driving gene expression in monocot plants. They are able to drive high-level transgene expression in almost all tissues and development stages in dicot or monocot plants, which results in not only excessive energy waste, but also morphological and physiological dysfunction frequently (Sinha et al., 1993; Cheon et al., 2004; Zhao et al., 2007). Inducible or tissue-specific promoters regulate target gene expression at specific conditions or tissues. Thus far some tissuespecific and stress-inducible promoters have been cloned and characterized. For example, pF128 promoter drives high-level GUS expression specific in the seeds of transgenic foxtail millet and maize (Pan et al., 2015). The promoters of $r d 29 A$ and $r d 29 B$ genes in Arabidopsis respond to multiple stimuli including salinity and drought (Shinozaki and Shinozaki, 1993). BADH promoter from Suaeda liaotungensis exhibits salt induced activity (Zhang et al., 2008). Rab16A promoter could up-regulate GUS expression in transgenic rice under salt stress (Rai et al., 2009). TsVP1 promoter from Thellungiella halophila displays strong activity in almost all tissues except the seeds and could be induced by salt stress in leaves and roots, especially root tips (Sun et al., 2010). Dreb2 promoter responds to drought stress in wheat ancestors (Tavakol et al., 2014). Salt overly sensitive gene promoter BjSOS2 from Brassica juncea responds to multiple stresses including salinity, drought and ABA (Kaur et al., 2015). However, the knowledge of inducible or tissue-specific promoters is still limited and the majority reported these specific promoters are weak ability of directing gene expression, which restricts their application.

Previous studies indicated that phosphoinositide (PI) signaling pathways are involved in environmental adaptation in higher plants, such as drought and salinity (Heilmann, 2009; Xue et al., 2009). Phosphatidylinositol (PtdIns) synthesis is the starting point of PI signaling pathway, which is synthesized by phosphatidylinositol synthase (PIS) from cytidinediphosphodiacylglycerol and D-myo-inositol (Löfke et al., 2008; Heilmann, 2009). The maize phosphatidylinositol synthase gene ( $Z m P I S$, GRMZM2G110646, MaizeGDB) has 11 exons and 10 introns. The cDNA sequence is 1707 bp including 648 bp protein coding sequence, $313 \mathrm{bp} 5^{\prime}$ UTR and $746 \mathrm{bp} 3^{\prime}$ UTR. Based on the length of its $5^{\prime}$ UTR, we speculated the transcription start site of ZmPIS may be located in the translation initiation codon ATG upstream of approximately 313 bp. Previously, our laboratory isolated an 1164 bp ZmPIS cDNA sequence containing complete protein coding region (GenBank accession no. AY370763). The transcript abundance of $Z m P I S$ is obviously increased by PEG, coldness and phytohormones (Sui et al., 2008). Overexpression of $Z m P I S$ in tobacco and maize improves drought stress tolerance through altering membrane lipid composition and increasing ABA synthesis (Zhai et al., 2012; Liu et al., 2013). However, the promoter region of this gene has not been characterized by far. Isolation and characterization of ZmPIS promoter will provide novel insight into understanding of PI signaling pathway and promoter resources for crop genetic improvement.

In this study, expression patterns and transcriptional activities of $5^{\prime}$ deleted ZmPIS promoter fragments in different sizes were characterized in transgenic tobacco. A 467 bp fragment with high promoter activity that enables salt or osmotic stress inducible gene expression and a novel 113 bp cis-regulatory core region that is critical for salt or osmotic stress response were identified.

\section{MATERIALS AND METHODS}

\section{Isolation of ZmPIS Promoter Sequence}

Primers were screened from the $2 \mathrm{~kb} 5^{\prime}$ flanking region of the ATG start codon of ZmPIS (GenBank accession. no. AY370763). The sequence was amplified from maize genomic DNA with primers pZmPISFR (Table 1) and confirmed by sequencing. Finally, the $1834 \mathrm{bp}$ fragment upstream of the translation initiation site (ATG) of ZmPIS was obtained by polymerase chain reaction (PCR) amplification using $\mathrm{PZ1}$ primers (Table 1) and considered as the full-length promoter.

\begin{tabular}{|c|c|c|}
\hline Name & Forward $\left(5^{\prime}-3^{\prime}\right)$ & Reverse $\left(5^{\prime}-3^{\prime}\right)$ \\
\hline pZmPISFR & gcccgctatgagcctaaac & tccagaggcgtaccgataa \\
\hline PZ1 & cgcggatccgcccgctatgagcctaaa & ccggaattctttgccagagggcaattg \\
\hline PZ2 & taaggatccgttctacttcttgaagg & ccggaattctttgccagagggcaattg \\
\hline PZ3 & aaaggatccccactagggcaatgggaa & ccggaattctttgccagagggcaattg \\
\hline PZ4 & acgggatccggcaatagaatgaaaaa & ccggaattctttgccagagggcaattg \\
\hline PZ5 & ctaggatccgcgcaaccgaacacgccg & ccggaattctttgccagagggcaattg \\
\hline PZ6 & aatggatcctatttggctatctgtat & ccggaattctttgccagagggcaattg \\
\hline PZ7 & ccgggatccatgatgcaaaaactagg & ccggaattctttgccagagggcaattg \\
\hline PZ8 & aagggatccttgccacaattcagat & ccggaattctttgccagagggcaattg \\
\hline p35SFR & aatggatccaagtctcaatagcccttt & tgagaattccgtattggctagagcagc \\
\hline p113FR & cgcggatccatgatgcaaaaactag & aaaactgcagcaaataaagcttgaacta \\
\hline HPTFR & cgtctgctgctccatacaa & tgtcctgcgggtaaatagc \\
\hline
\end{tabular}

The underlined sites are the sites for the digestion of restriction enzymes BamH1. The underlined italicized sites are the sites for the digestion of restriction enzymes ECOR1. 


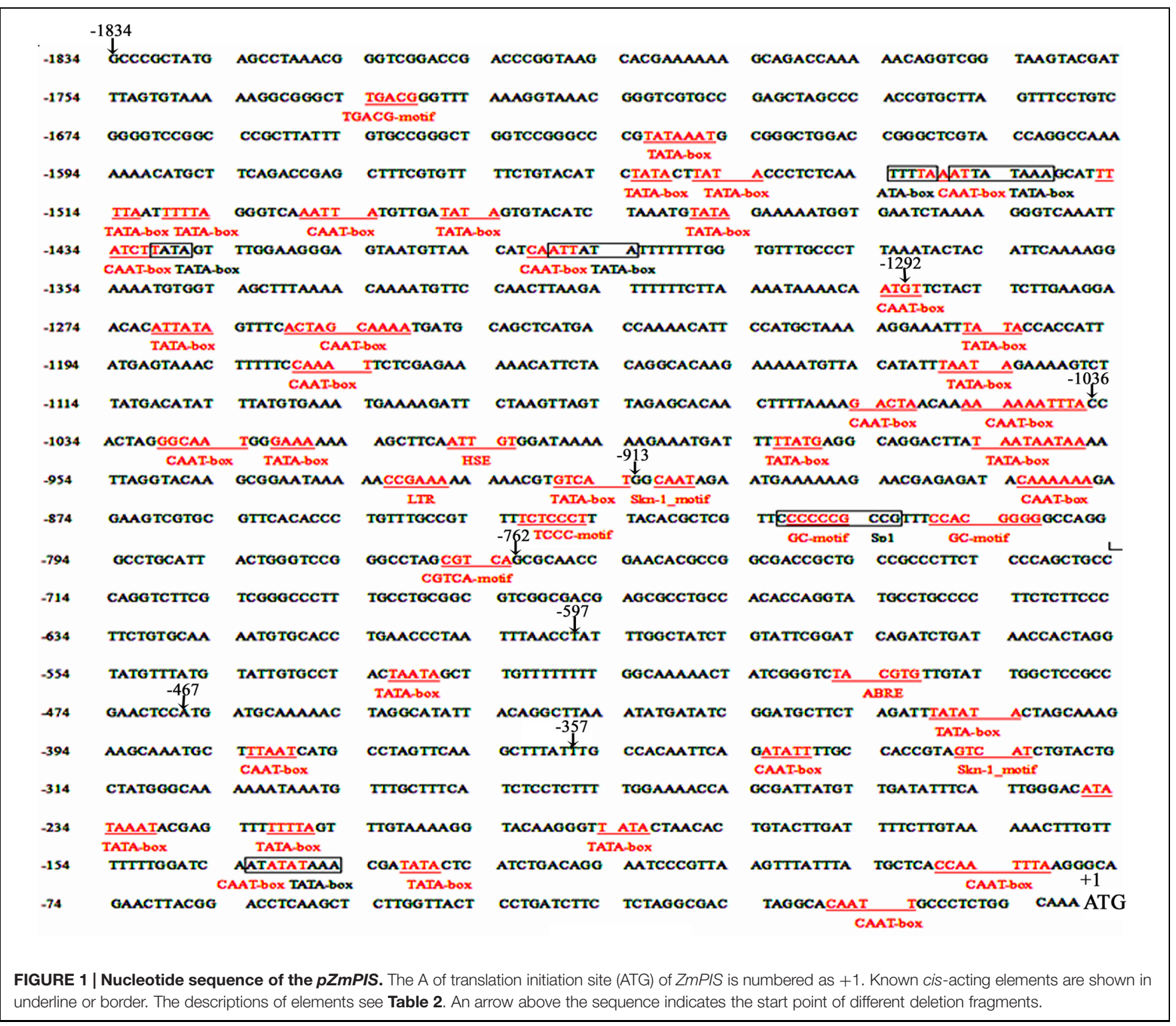

\section{Bioinformatic Analysis of the Promoter Sequence}

The cis-acting elements of 1834 bp ZmPIS promoter ( $p Z m P I S$ ) sequence were analyzed using online programs PLACE $\left({ }^{1} \mathrm{Higo}\right.$ et al., 1999) and PlantCARE ( ${ }^{2}$ Lescot et al., 2002). The position and description of cis-acting elements are present in Figure $\mathbf{1}$ and Table 2.

\section{Construction of Promoter::GUS Fusion Plasmids}

Eight $5^{\prime}$ deleted fragments (PZ1-PZ8) in different size $(-1834$, $-1292,-1036,-913,-762,-597,-467$, and -357 bp to -1 bp; the translation initiation site was designated as “ +1 ”; Figure 2)

${ }^{1}$ http://www.dna.affrc.go.jp/PLACE/

${ }^{2}$ http://bioinformatics.psb.ugent.be/webtools/plantcare/html/ were amplified by PCR from the $1834 \mathrm{bp}$ promoter region of $\mathrm{ZmPIS}$ with the oligonucleotide primers listed in Table 1. For the generation of pZmPIS::GUS constructs, the PCR products were subsequently constructed into the pCAMBIA1391Z vector (Cambia, Australia) with BamH1/EcoR1 restriction sites and confirmed by sequencing. The resulting constructs were used for tobacco (Nicotiana benthamiana) stable transformation.

The minimal CaMV35S promoter fragment $(-46 \sim+10 \mathrm{bp})$ was amplified by PCR using primers p35SFR (Table 1). The amplified fragment was confirmed by sequencing and then the fragment was cloned into the Pst1/Spe1 sites upstream of the GUSA reporter gene in vector pCAMBIA1304 (Cambia, Australia). The plasmid was designated as P-mini 35S. The $113 \mathrm{bp}$ sequence of the ZmPIS promoter ( $-467 \sim-355 \mathrm{bp}$ ) was cloned by PCR using the primers p113FR (Table 1) and then confirmed by sequencing. The amplified fragment was inserted into the BamH1/Pst1 sites of the P-mini 35S vector. The construct was 
TABLE 2 | Known cis-acting elements in the pZmPIS using the PlantCARE and PLACE databases.

\begin{tabular}{|c|c|c|}
\hline Cis-elements & Description & No \\
\hline CAAT-box & $\begin{array}{l}\text { Common cis-acting element in promoter and } \\
\text { enhancer regions }\end{array}$ & 16 \\
\hline CTAG-motif & Unknown & 1 \\
\hline HSE & $\begin{array}{l}\text { Cis-acting element involved in heat stress } \\
\text { responsiveness }\end{array}$ & 1 \\
\hline LTR & $\begin{array}{l}\text { Cis-acting element involved in low-temperature } \\
\text { responsiveness }\end{array}$ & 1 \\
\hline Skn-1_motif & $\begin{array}{l}\text { Cis-acting regulatory element required for } \\
\text { endosperm expression }\end{array}$ & 2 \\
\hline TATA-box & $\begin{array}{l}\text { Core promoter element around }-30 \text { of } \\
\text { transcription start }\end{array}$ & 25 \\
\hline TCCC-motif & Part of a light responsive element & 1 \\
\hline TGACG-motif & $\begin{array}{l}\text { Cis-acting regulatory element involved in the } \\
\text { MeJA-responsiveness }\end{array}$ & 1 \\
\hline ABRE & $\begin{array}{l}\text { Cis-acting element involved in the abscisic acid } \\
\text { responsiveness }\end{array}$ & 1 \\
\hline CGTCA-motif & $\begin{array}{l}\text { Cis-acting regulatory element involved in the } \\
\text { MeJA-responsiveness }\end{array}$ & 1 \\
\hline GC-motif & $\begin{array}{l}\text { Enhancer-like element involved in anoxic } \\
\text { specific inducibility }\end{array}$ & 2 \\
\hline Sp1 & Light responsive element & 1 \\
\hline
\end{tabular}

The position of cis-acting elements in the sequence of pZmPIS was shown in Figure 1. MeJA, methyl jasmonate; Sp1, Sp1 transcription factor family binding sites.

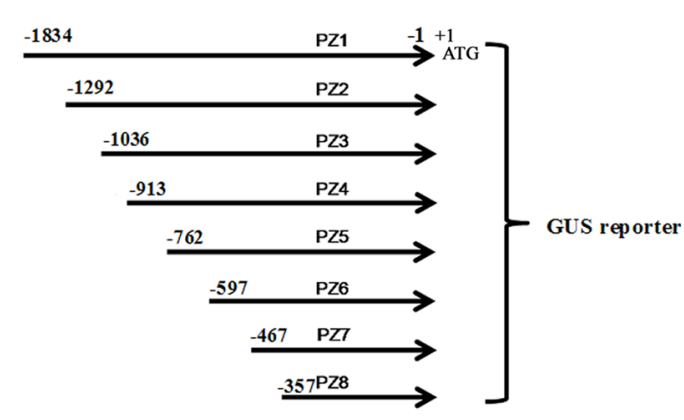

FIGURE 2 | The constructs of the truncated fragments of pZmPIS fused with GUS. A series of $5^{\prime}$ deleted fragments of $p Z m P I S$ were placed upstream of the GUS reporter gene. The numbers indicate the nucleotide position from the translational initiate site, ATG $(A$ as +1$)$.

named P-113 bp mini 35S. These plasmids were used for tobacco transient assay.

In addition to these constructs above, pCAMBIA1304 vector containing the CaMV35S promoter upstream from the GUSA reporter gene was used as a positive control.

\section{Culture and Stable Transformation of Tobacco}

Tobacco seeds were sterilized with $70 \%$ ethanol for $1 \mathrm{~min}, 10 \%$ $\mathrm{NaClO}$ for $10 \mathrm{~min}$, then washed with sterile water for 5-6 times, 5-7 min every time. The seeds were germinated at $25^{\circ} \mathrm{C}$ for 7 days. Then 7 -days-old seedlings were transferred into culture bottles containing nutrient medium $\left(\mathrm{KNO}_{3} 9.4 \mathrm{mM}, \mathrm{NH}_{4} \mathrm{NO}_{3}\right.$
$10.3 \mathrm{mM}, \mathrm{MgSO}_{4} 0.75 \mathrm{mM}, \mathrm{KH}_{2} \mathrm{PO}_{4} 0.62 \mathrm{mM}, \mathrm{CaCl}_{2} 1.5 \mathrm{mM}$, KI $2.59 \mu \mathrm{M}, \mathrm{H}_{3} \mathrm{BO}_{3} 65 \mu \mathrm{M}, \mathrm{MnSO}_{4} 50 \mu \mathrm{M}, \mathrm{Na}_{2} \mathrm{MoO}_{4} 0.62 \mu \mathrm{M}$, $\mathrm{ZnSO}_{4} 17.39 \mu \mathrm{M}, \mathrm{CuSO}_{4} 0.05 \mu \mathrm{M}, \mathrm{CoCl}_{2} 0.052 \mu \mathrm{M}$, Fe-EDTA $50 \mu \mathrm{M}$, inositol $0.27 \mathrm{mM}$, nicotinic acid $2.03 \mu \mathrm{M}, \mathrm{VB}_{6} 1.22 \mu \mathrm{M}$, $\mathrm{VB}_{1} 0.15 \mu \mathrm{M}$, Gly $13 \mu \mathrm{M}$, sucrose $30 \mathrm{~g} / \mathrm{L}$, agar $0.7 \%, \mathrm{pH} 6.0$ ) and grown in a growth chamber at $25^{\circ} \mathrm{C}$ with a cycle of $16 \mathrm{~h}$ light (220-260 $\left.\mu \mathrm{mol} \mathrm{m}^{-2} \mathrm{~s}^{-1}\right)$ for 6 weeks until transformation.

The pCAMBIA1304 and recombinant plasmids PZ1-PZ8 were introduced into the Agrobacterium tumefaciens strain GV3101 using a freeze-thaw method. The A. tumefaciensmediated transformation of tobacco leaf disks was performed as previously described by Voelker et al. (1987) with minor modifications. Transformed shoots were screened on MS medium supplemented with $1.0 \mathrm{mg} / \mathrm{L}$ 6-benzylaminopurine, $0.1 \mathrm{mg} / \mathrm{L}$ indole-3-acetic acid, $400 \mathrm{mg} / \mathrm{L}$ cefotaxime, and $15 \mathrm{mg} / \mathrm{L}$ hygromycin B. Regenerated shoots were rooted on MS medium containing $200 \mathrm{mg} / \mathrm{L}$ cefotaxime and $15 \mathrm{mg} / \mathrm{L}$ hygromycin $\mathrm{B}$. The regenerated plants were cultivated in soil under $25-28^{\circ} \mathrm{C}$ (day) and $19-22^{\circ} \mathrm{C}$ (night) with a cycle of $16 \mathrm{~h}$ of light (220-260 $\mu \mathrm{mol} \mathrm{m} \mathrm{m}^{-2} \mathrm{~s}^{-1}$ ). The T0 positive transformants were screened out for propagation by PCR of the hygromycin resistant gene harbored in the pCAMBIA1391Z and pCAMBIA1304 vectors with the primers HPTFR (Table 1) and GUS staining (Supplementary Figure S1). The homozygous transgenic lines of T3 generation with a single copy of promoter::GUS insert were selected for subsequent analyses via segregation ratio analysis.

\section{Salinity and Osmotic Stress Treatments}

Transgenic tobacco plants were grown in a bottle containing $1 \mathrm{~L} 1 / 2$ MS liquid medium ( $\mathrm{pH}$ 6.0) under $25-28^{\circ} \mathrm{C}$ (day) and $19-22^{\circ} \mathrm{C}$ (night) with a cycle of $16 \mathrm{~h}$ light (220$\left.260 \mu \mathrm{mol} \mathrm{m} \mathrm{m}^{-2} \mathrm{~s}^{-1}\right)$. Sixty-days-old tobacco plants were subjected to stress treatments. For salinity, whole plants were incubated in the liquid 1/2 MS medium supplemented with $200 \mathrm{mM} \mathrm{NaCl}$ for 1, 3, 6, 12, 24, 48, and $72 \mathrm{~h}$. For osmotic stress, tobacco plants were incubated in the liquid 1/2 MS medium supplemented with 18\% (w/v) polyethylene glycol 6000 (PEG 6000). The control plants were grown in $1 / 2 \mathrm{MS}$ liquid medium. Leaf tissues were sampled for GUS histochemical staining immediately and frozen in liquid nitrogen and stored at $-80^{\circ} \mathrm{C}$ for GUS fluorometric assays. All the experiments were repeated three times with independent samples.

\section{Histochemical and Fluorometric GUS Assays}

Three independent transgenic lines and at least five individual plants from each construct were used for GUS expression assay. Histochemical GUS staining was performed as described by Jefferson et al. (1987) with minor modifications. Briefly, the tissues were incubated in staining solution containing $50 \mathrm{mM}$ sodium phosphate buffer $(\mathrm{pH} 7.0), 0.5 \mathrm{mM}$ potassium ferrocyanide, $0.5 \mathrm{mM}$ potassium ferricyanide, $0.1 \%$ Triton $\mathrm{X}$ 100, $10 \mathrm{mM}$ EDTA, and $1 \mathrm{mM} 5$-bromo-4-chloro-3-indolyl- $\beta$ D-glucuronic acid (X-Gluc; Sangon, Shanghai, China). Following vacuum infiltration, the samples were incubated at $37^{\circ} \mathrm{C}$ for $24 \mathrm{~h}$. The tissues decolorized in $70 \%$ ethanol were observed 
and recorded using a digital still camera (Sony, DSC-F828). Fluorometric assay of GUS activity was performed as described by Jefferson et al. (1987) with minor modifications. In brief, leaf tissues were homogenized in a $4^{\circ} \mathrm{C}$ extraction buffer containing $50 \mathrm{mM}$ sodium phosphate ( $\mathrm{pH} 7.0$ ), 0.1\% Triton X-100, $10 \mathrm{mM}$ EDTA, $0.1 \%$ sodium lauryl sarcosine and $10 \mathrm{mM}$ dithiothreitol. After centrifugation at $10000 \mathrm{~g}$ for $15 \mathrm{~min}$ at $4^{\circ} \mathrm{C}$ the activity of the supernatant was detected in working buffer containing $1 \mathrm{mM}$ 4-methylumbelliferyl-b-glucuronide (4-MUG, Sigma, USA) at $37^{\circ} \mathrm{C}$. The reaction was terminated by adding $200 \mathrm{mM} \mathrm{Na}_{2} \mathrm{CO}_{3}$ to a final concentration of $180 \mathrm{mM}$. The fluorescence was quantified using a fluorescence spectrophotometer (HITACHI F-4600, Japan) at the excitation and emission wavelengths of 365 and $455 \mathrm{~nm}$, respectively. Protein concentration was determined as described by Bradford (1976). The GUS activity was normalized with five 4-MU standards (10 mM, $1 \mathrm{mM}, 100 \mathrm{nM}, 50 \mathrm{nM}$, and $10 \mathrm{nM}$ ) under control conditions and calculated as nmol of 4-MU per mg protein per minute.

\section{GUS Transient Assay in Tobacco Leaves}

GUS transient assay was performed using the leaves of 7weeks-old tobacco plants as described by Yang et al. (2000). A. tumefaciens GV3101 of each construct was grown on YEP medium containing rifampicin $(50 \mathrm{mg} / \mathrm{L})$ and kanamycin $(50 \mathrm{mg} / \mathrm{L})$ at $28^{\circ} \mathrm{C}$ for $18 \mathrm{~h}$. The bacteria were harvested by centrifugation for $15 \mathrm{~min}$ at $6000 \mathrm{~g}$ and re-suspended in the transformation buffer (10 mm MES, $\mathrm{pH} 5.6,10 \mathrm{~mm} \mathrm{MgCl}_{2}$, $100 \mu \mathrm{m}$ acetosyringone) to an OD 600 of 0.6 for leaf infiltration. After agro-infiltration at the abaxial surfaces of tobacco leaves using a needleless syringe, the plants were maintained in a moist chamber at $25^{\circ} \mathrm{C}$ for 2 days. For salinity and osmotic stress, the infiltrated leaves were incubated in the liquid 1/2 MS medium supplemented with $200 \mathrm{mM} \mathrm{NaCl}$ and 18\% (w/v) PEG 6000 for $24 \mathrm{~h}$, respectively. The infiltrated leaves grown in the liquid 1/2 MS medium were treated as control. Finally, at least 15 independent infiltrated leaves from different plants were used for histochemical GUS staining and fluorometric assay of GUS activity. The entire experiments were repeated three times.

\section{Data Analysis}

All GUS fluorometric assays were repeated at least three times, and the results were expressed as mean values \pm SD (standard deviation). The statistical significance of quantitative data was determined using Student's $t$-test $(n=3, P<0.05$; Sigmaplot $12.0)$ at a $95 \%$ confidence level.

\section{RESULTS}

\section{Isolation and Sequence Analysis of the pZmPIS}

Based on the annotation of maize genome, the $1834 \mathrm{bp}$ promoter sequence of ZmPIS upstream of the translation initiation site (ATG) was isolated from maize genomic DNA. We analyzed the promoter sequence for the presence of putative cis-acting elements through PLANTCARE and PLACE databases. The results showed that the $1834 \mathrm{bp}$ promoter sequence contains a number of TATA-box and CAAT-box core cis-acting elements. Some cis-acting elements in response to multiple environmental stimuli were also present, including two types of light responsive elements [TCCC-motif and Sp1 (Sp1 transcription factor family binding sites)], two types of MeJA (methyl jasmonate) responsive elements (TGACG-motif and CGTCA-motif), two known elements required for endosperm expression (Skn1_motif), a enhancer-like element involved in anoxic specific inducibility (GC-motif), a heat stress responsive element (HSE), a low-temperature responsive element (LTR), an abscisic acid responsive element (ABRE) and a unknown element CTAGmotif (Figure 1 and Table 2). However, known salinity or osmotic stress inducible cis-acting elements were not harbored in the $p Z m P I S$ sequence, although the expression of ZmPIS could be obviously induced by $\mathrm{NaCl}$ or PEG treatment (Sui et al., 2008; Zhai et al., 2012; Liu et al., 2013).

\section{Activity of $5^{\prime}$ Deleted Fragments of ZmPIS Promoter in Transgenic Tobacco}

Six to ten independent transgenic lines for each construct (PZ1-PZ8 and CaMV35S) were screened in T2 generation by histochemical GUS staining. Three transgenic lines segregating 3:1 for each construct were selected, and the T3 homozygous generation was chosen for further analysis. The results of GUS staining showed that PZ1-PZ8 promoter fragments were capable of directing GUS expression, but their promoter activities in transgenic tobaccos were obviously different.

In order to evaluate the transcriptional activities of PZ1PZ8 under normal condition and identify core functional region of $Z m P I S$ promoter, fluorometric GUS assays were further performed with transgenic tobacco leaves from different constructs (Figure 3). The promoter activities of PZ1-PZ6 were relatively weak, while PZ7 and PZ8 were able to drive strong GUS expression. Among them, the GUS expression driven by PZ7 was obviously higher than these of PZ1-PZ6 and PZ8, which corresponds to approximately 20 folds of GUS activity of full length promoter PZ1 and about 4 and

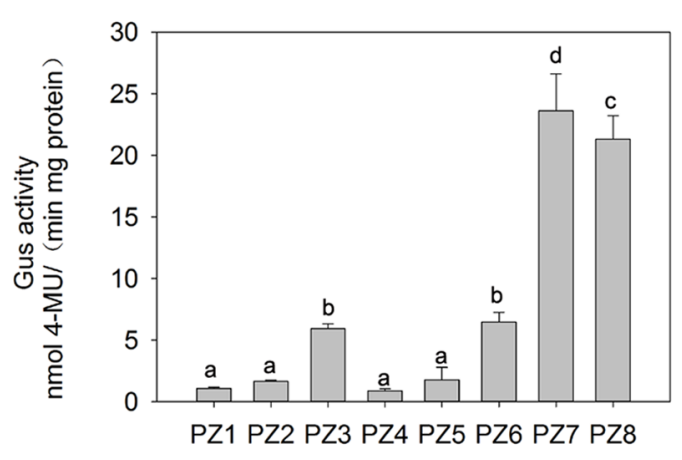

FIGURE 3 | Fluorometric GUS assays of PZ1-PZ8 transgenic tobacco plants. The values are the mean \pm standard deviation from three independent transgenic lines and each line five individual plants for each construct. Different lowercase letters above the bars indicate significant differences at $P<0.05$. 
1.1 folds of PZ6 and PZ8. These results suggested that the 131 bp $(-467 \sim-597$ bp) sequence between PZ6 and PZ7 may contain cis-acting elements that inhibit gene expression, and PZ7 fragment (467 bp, $-467 \sim-1 \mathrm{bp}$ ) may be the core functional region of ZmPIS promoter which contains multiple core cis-acting elements CAAT-box and TATA-box (Figure 1).

\section{Expression Pattern of PZ1 and PZ7 Transgenic Tobacco}

To profile the expression of transgenic tobacco plants driven by PZ1 (full length promoter), PZ7 and CaMV35S under normal condition, the 2-weeks-old independent transgenic tobacco plants, flowers, fruits, and seeds were subjected to histochemical staining (Figure 4). CaMV35S transgenic plants displayed the highest GUS expression intensity among the tested constructs. GUS expression activity for PZ1 was the weakest in all tissues and almost not detected in the roots, stems and cotyledons of 2weeks-old seedlings and seeds. The deletion of 1367 bp $(-1834$ to $-467 \mathrm{bp}$ ) resulted in significantly strong GUS activity in all tissues. High GUS expression intensity was detected in almost all tissues of PZ7 plants including the leaves, cotyledon and stem of 2-weeks-old seedlings, and petals, sepals, stigma, and seed except the roots of 2 -weeks-old seedlings. Taken together, the promoter deletion segment PZ7 was sufficient to drive high-level gene expression in transgenic tobacco under normal condition.

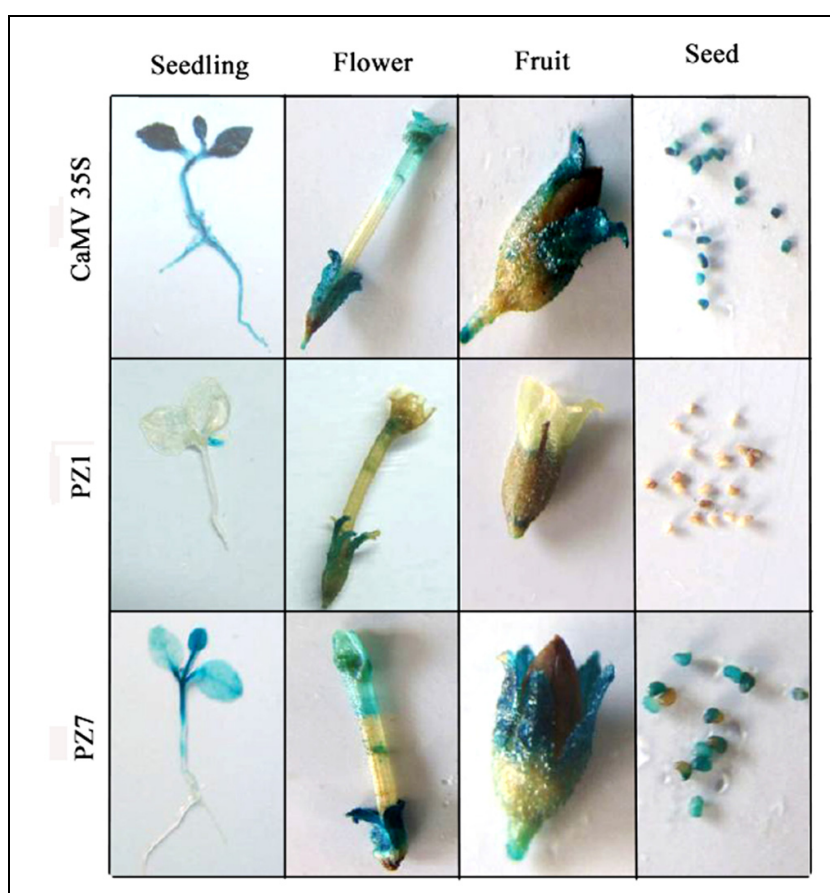

FIGURE 4 | Histochemical GUS staining in tissues of PZ1, PZ7, and CaMV35S transgenic tobacco. Two-weeks-old tobacco seedlings, flowers, fruits, and seeds were incubated in staining solution at $37^{\circ} \mathrm{C}$ for $24 \mathrm{~h}$. Then the samples were observed and photographed after decolorization.

\section{Salinity and Osmotic Stress Responses Mediated by $5^{\prime}$ Deleted Fragments of pZmPIS in Transgenic Tobacco}

The transcript abundance of ZmPIS can be regulated by multiple abiotic stresses including drought and salt (Sui et al., 2008; Zhai et al., 2012; Liu et al., 2013). However, bioinformatic analysis indicated that the $1834 \mathrm{bp} p Z m P I S$ seguence does not harbor any known salinity or osmotic stress inducible cis-acting elements. In order to investigate the regulatory machinery involved in ZmPIS activation upon salinity or osmotic stresses, promoter activities of PZ1-PZ8 were determined in leaves of 60-days-old transgenic tobacco plants subject to $200 \mathrm{mM} \mathrm{NaCl}$ or 18\% PEG 6000 treatment in a time-course experiment, respectively. Positive (transformed CaMV35S promoter tobacco) and negative (wild type) control seedlings were also treated in parallel. Because of the original high GUS expression levels in leaves of 35S, PZ7 and PZ8 transgenic tobacco plants, it is difficult to see an obvious change in expression level just by GUS staining (Figures 5A and 6A). In order to make clear the difference of GUS expression between the series of mutant before and after stresses, we also measured GUS enzyme activity (Figures 5B and 6B). The results showed that there was no obvious difference between stress-treated groups and control groups after 1, 3, and 6 h stress treatments. PZ1PZ7 plants started a stress-induced tendency after $12 \mathrm{~h}$ treatment, and the GUS expression intensity of PZ1-PZ7 plants displayed a significant increase compared to the controls after 24,48 , and $72 \mathrm{~h}$ salinity or osmotic stress treatments. GUS enzyme activities of PZ1-PZ7 were obviously induced up to more than twofolds in the leaves under salinity or osmotic stress treatment for $24 \mathrm{~h}$ and maintained at a relatively high expression level with 48 and $72 \mathrm{~h}$ treatments. However, GUS staining intensity and fluorometric activity of the leaves in PZ8 and CaMV35S transgenic tobacco were stable during the stress treatment. Therefore, PZ1-PZ7 displayed obviously salinity and osmotic stress-inducing activity, while PZ8 did not. These results suggested that the $110 \mathrm{bp}$ fragment of $p Z m P I S$ between PZ7 and PZ8 ( -467 to $-357 \mathrm{bp}$ ) may contain functional elements involved in salinity or osmotic stress response. Therefore, ZmPIS promoter could well respond to salinity or osmotic stress. Notably, among transgenic tobacco lines of $5^{\prime}$ deleted $p Z m P I S$ fragments, PZ7 had the highest promoter activity and reached 20 times more than PZ1 and 3 times more than PZ6 under both normal and salinity or osmotic stress conditions. Under normal condition, the activity of PZ7 was about 1.1 fold of PZ8 and 0.2 fold of CaMV35S, while reached twofold more than PZ8 and about 50\% of CaMV35S promoter under salinity or osmotic stress. This implied that PZ7 (467 bp; -467 to $-1 \mathrm{bp}$ ) enables high level gene expression and salinity or osmotic stress inducibility.

\section{The 113 bp cis-Regulatory Region was Sufficient for the Salinity and Osmotic Stress Responses}

To avoid the salinity or osmotic stress response element being at the right boundary of $110 \mathrm{bp}(-467$ to $-357 \mathrm{bp})$ DNA sequence, we extended three bases to the right. To investigate if 


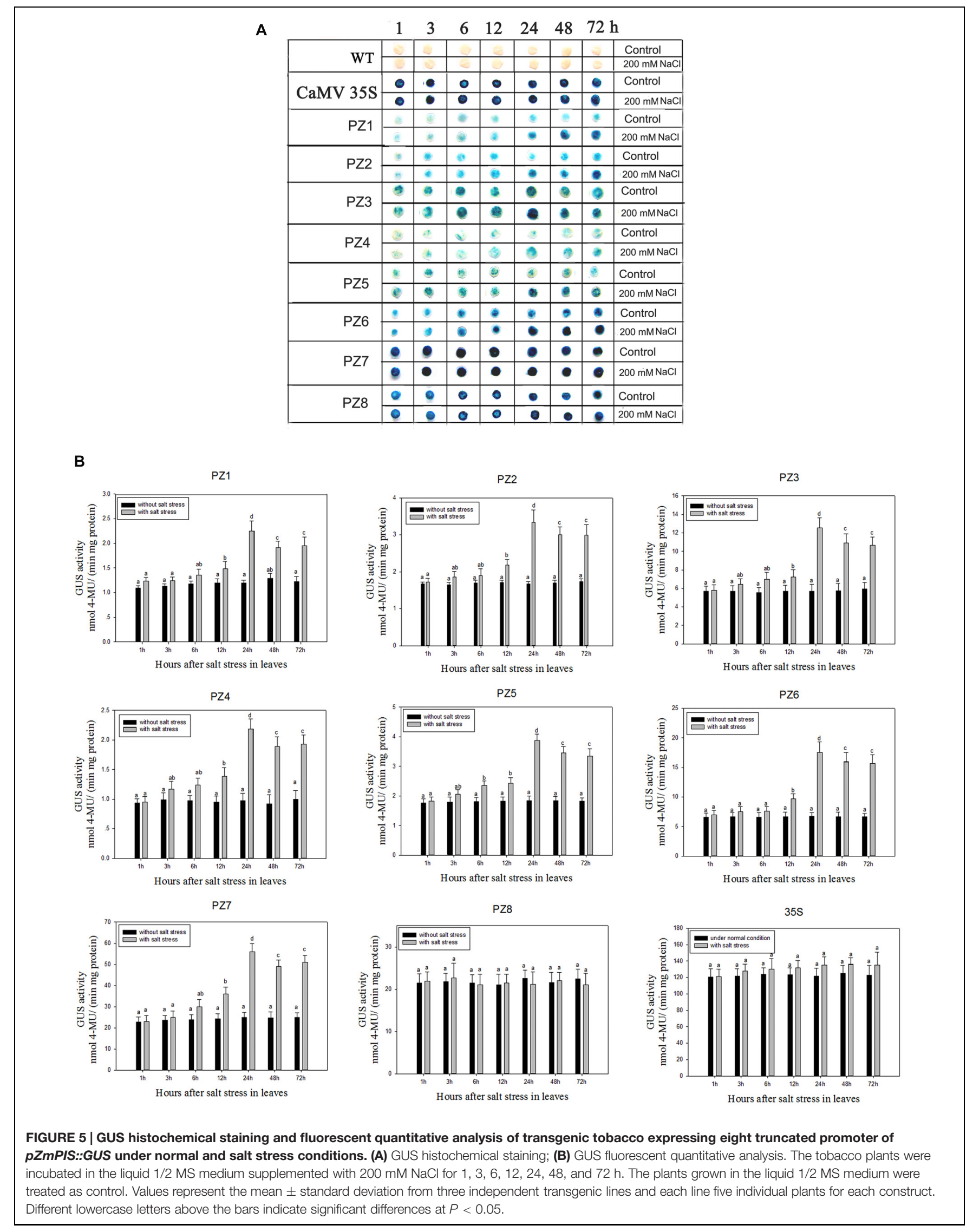


A

\begin{tabular}{|c|c|c|c|c|c|c|c|c|}
\hline & 1 & 3 & 6 & 12 & 24 & 48 & $72 \mathrm{r}$ & \\
\hline \multirow{2}{*}{ WT } & $\infty$ & $\theta$ & $\theta$ & 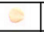 & 5 & $\theta$ & 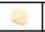 & Control \\
\hline & 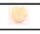 & $\theta$ & 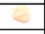 & $\square$ & 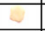 & 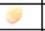 & 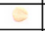 & $18 \%$ PEG \\
\hline \multirow{2}{*}{ CaMV 35S } & - & - & - & - & - & • & - & Control \\
\hline & $\bullet$ & 0 & $\bullet$ & $\cdot$ & $\bullet$ & - & $\bullet$ & $18 \%$ PEG \\
\hline \multirow{2}{*}{ PZ1 } & 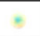 & ${ }^{2}$ & $\varepsilon$ & 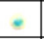 & $\mathrm{c}$ & $*$ & $\theta$ & Control \\
\hline & 3 & , & $s$ & $\Rightarrow$ & $\cdot$ & 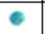 & 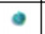 & $18 \%$ PEG \\
\hline \multirow{2}{*}{ PZ2 } & $\bullet$ & e & , & 6 & $\bullet$ & 0 & $=$ & Control \\
\hline & 9 & 9 & $\circ$ & $\bullet$ & $\bullet$ & $\bullet$ & $\bullet$ & $18 \%$ PEG \\
\hline \multirow{2}{*}{ PZ3 } & 5 & $\theta$ & 3 & $\bullet$ & 0 & 9 & $*$ & Control \\
\hline & 9 & 5 & $\theta$ & $\bullet$ & - & - & - & $18 \%$ PEG \\
\hline \multirow{2}{*}{ PZ4 } & - & 3 & 6 & 3 & 0 & 3 & a & Control \\
\hline & $\theta$ & 3 & 6 & 6 & 8 & 8 & 2 & $18 \%$ PEG \\
\hline \multirow{2}{*}{ PZ5 } & * & $\Rightarrow$ & 9 & 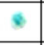 & 5 & 3 & 8 & Control \\
\hline & 6 & $*$ & + & 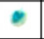 & $\cdot$ & 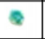 & 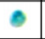 & 18\% PEG \\
\hline \multirow{2}{*}{ PZ6 } & $\theta$ & $\bullet$ & $\bullet$ & $\bullet$ & 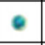 & - & 0 & Control \\
\hline & 9 & $\bullet$ & $\bullet$ & $\bullet$ & - & $\bullet$ & $\bullet$ & $18 \%$ PEG \\
\hline \multirow[t]{2}{*}{ PZ7 } & - & - & $\bullet$ & - & $\bullet$ & $\bullet$ & - & Control \\
\hline & $\bullet$ & $\bullet$ & $\bullet$ & • & $\bullet$ & - & $\bullet$ & $18 \%$ PEG \\
\hline \multirow[t]{2}{*}{ PZ8 } & $\bullet$ & 0 & $\bullet$ & 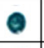 & - & - & - & Control \\
\hline & 0 & 0 & 인 & 인 & - & - & - & $18 \%$ PEG \\
\hline
\end{tabular}

B
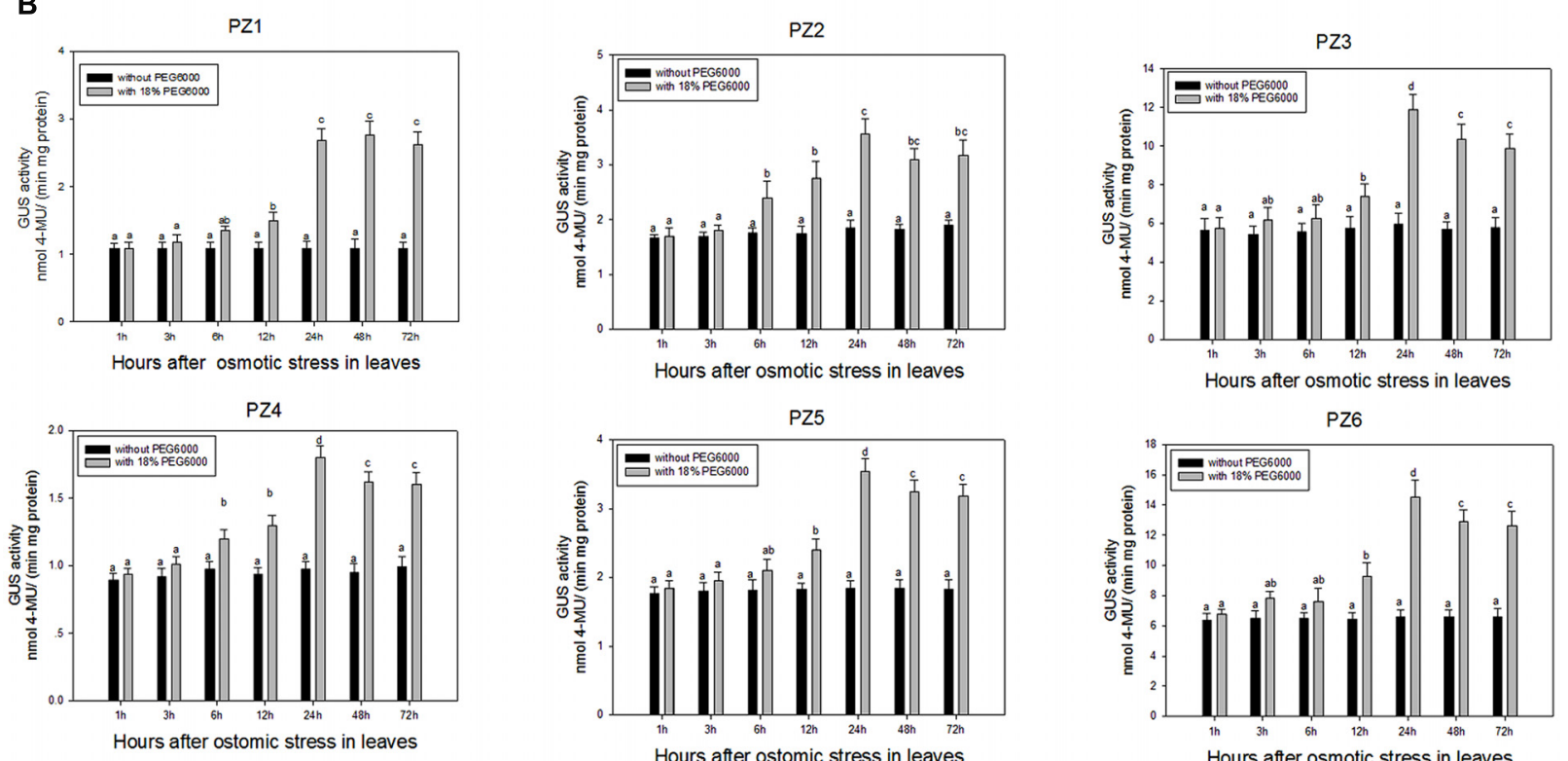

Hours after ostomic stress in leaves

PZ8
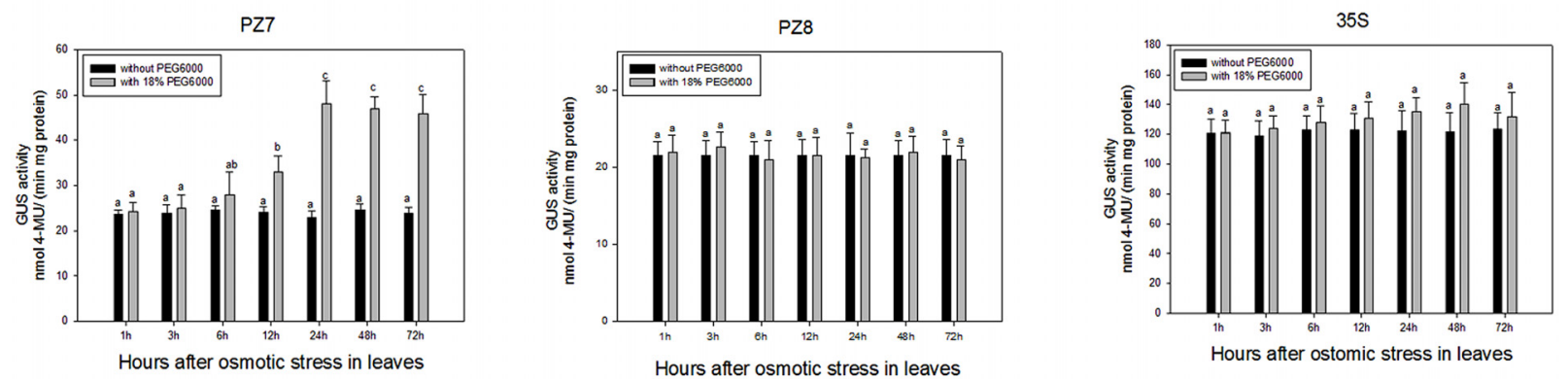

FIGURE 6 | GUS histochemical staining and fluorescent quantitative analysis of transgenic tobacco expressing eight truncated promoter of pZmPIS::GUS under normal and osmotic stress conditions. (A) GUS histochemical staining. (B) GUS fluorescent quantitative analysis. The tobacco plants were incubated in the liquid 1/2 MS medium supplemented with 18\% (w/v) PEG 6000 for 1, 3, 6, 12, 24, 48, and $72 \mathrm{~h}$. The plants grown in the liquid 1/2 MS medium were treated as control. Values represent the mean \pm standard deviation from three independent transgenic lines and each line five individual plants for each construct. Different lowercase letters above the bars indicate significant differences at $P<0.05$. 

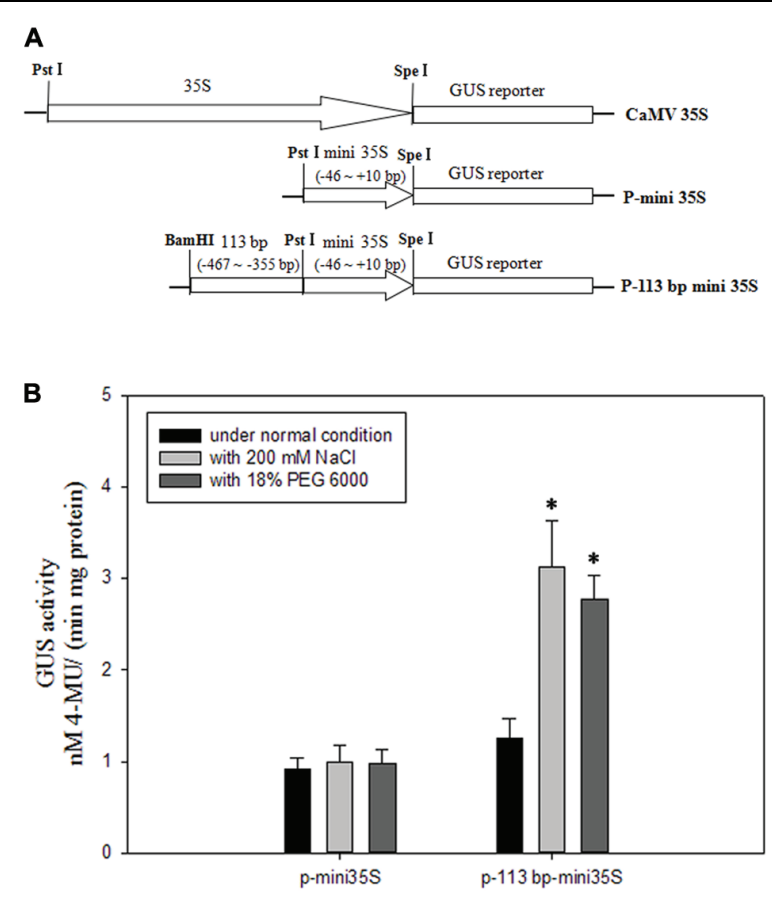

FIGURE 7 | GUS transient assays in tobacco leaves. (A) Fusion constructs used in the transient assay. The CaMV35S represent $35 S$ full length promoter. P-mini 35S represent the mini 35S (-46 to +10 bp) promoter. The test construct P-113 bp mini 35S in which the $113 \mathrm{bp}$ region ( -467 to $-355 \mathrm{bp}$ ) identified in the pZmPIS was fused to the P-mini 35S promoter to drive the GUS expression. (B) GUS enzymatic activity resulting from the transiently transformed tobacco leaves with constructs P-mini 35S and $\mathrm{P}-113$ bp mini $35 \mathrm{~S}$ under both normal and $200 \mathrm{mM} \mathrm{NaCl}$ or $18 \%(\mathrm{w} / \mathrm{v})$ PEG 6000 treatment for $24 \mathrm{~h}$. Results are mean \pm standard deviation from three experiments $(n=15)$. The asterisk indicates a significant difference at $P<0.05$.

the 113 bp region $(-467$ to $-355 \mathrm{bp}$, relative to the translational initiate site ATG) identified in the $p Z m P I S$ was sufficient for the salinity or osmotic stress response, we constructed a P-113 bp mini 35 sector and detected its activity under normal and salinity or osmotic stress conditions by Agrobacterium-mediated GUS transient assay in tobacco leaves (Figure 7). Under normal condition, p-113 bp mini 35 S promoter had a higher activity than the P-mini $35 \mathrm{~S}$ promoter. Bioinformatic analysis showed that the 113 bp fragment contains a CAAT-box with enhancer function, which may result in the increment of its promoter activity. GUS expression intensity of the P-113 bp mini 35 S of transiently transfected tobacco leaves had a significant increment under salinity or osmotic stress condition, while the activity of the P-mini 35S promoter was not obviously changed after salt or osmotic stress treatment (Figure 7B and Supplementary Figure S2). Therefore, the 113 bp region ( -467 to $-355 \mathrm{bp}$ ) was sufficient for mediating salinity and osmotic stress transcriptional responses.

To better detect the transformation efficiency, the tobacco leaves infiltrated by CaMV35S::GUS fusion plasmid and the untransformed tobacco leaves (WT) were also used in each experiment as positive and negative controls, respectively. These leaves infiltrated with CaMV35S promoter plasmid had a very strong GUS activity, while these untransformed leaves had no GUS activity (Supplementary Figure S2).

\section{DISCUSSION}

Phosphoinositide signaling is involved in plant stress responses, including osmosis, temperature, drought, and salinity (König et al., 2007; Xue et al., 2007, 2009; Perera et al., 2008; Heilmann, 2009; Munnik and Vermeer, 2010). In eukaryotes, PI signaling start with PtdIns synthesis. As one of the major phospholipids, PtdIns is not only a structural component of cell membranes, but also the precursor of the several types of second messengers that allow higher plants to cope with multiple environments (Welti et al., 2002; Wang, 2004; Löfke et al., 2008). Due to the importance of PtdIns, PIS gene had brought additional attention that catalyzed the synthesis of PtdIns. Several studies showed that PIS participated in plant stress responses, including salinity and osmotic stress (Lin et al., 2004; Das et al., 2005; Sui et al., 2008; Zhai et al., 2012; Liu et al., 2013). In the study, we characterized its promoter to understand the functions of $Z \mathrm{mPIS}$ in response to salinity and osmotic stresses and explore its prospect for application as a stress-inducible promoter. The analysis of $5^{\prime}$ deleted mutants of $p Z m P I S$ (PZ1-PZ8) under salinity or osmotic stress conditions revealed that a 113 bp segment $(-467 \sim$ $-355 \mathrm{bp}$, upstream of the translational initiate site ATG) is the key region for $Z m P I S$ response to salinity or osmotic stress. The GUS transient assay in tobacco leaves showed that the $113 \mathrm{bp}$ segment was sufficient for the response of salinity or osmotic stress. However, only two types of cis-acting elements including two TATA-boxes and a CAAT-box were found in the $113 \mathrm{bp}$ region by online program PLACE and PLNATCARE (Figure 8). The TATA-box is core promoter element that functions in the transcription start of gene expression. The CAAT-box is common cis-acting element in promoter that general is with enhancer activity. Therefore, the $113 \mathrm{bp}$ region may contain some unknown cis-acting elements that are crucial for ZmPIS response to salinity and osmotic stresses. Thus identification of the minimal cis-elements in this region and interacting proteins that play important roles in the regulation of $Z m P I S$ promoter will be meaningful for understanding the salinity or osmotic stress responsive mechanism of plant PI signaling in future.

Promoters play important roles in initiating gene transcription and regulating gene expression temporally and spatially. Transgenic technology is an important technique for crop improvement. Application of an efficient promoter is essential to develop a vector that enables transgene expression at desired levels (Potenza et al., 2004). The development of tissue specificity or inducible promoters attracted great attention in plant genetic engineering (Kumpatla et al., 1998; Zavallo et al., 2010). The usage of inducible promoters to drive the expression of target genes under certain environment conditions can prevent unnecessary gene expression caused by constitutive promoters. In addition, transgenic safety was also seriously considered that the use of virus- or bacteria-derived promoters were limited such as CaMV35S (Koia et al., 2013). We identified a 467 bp 


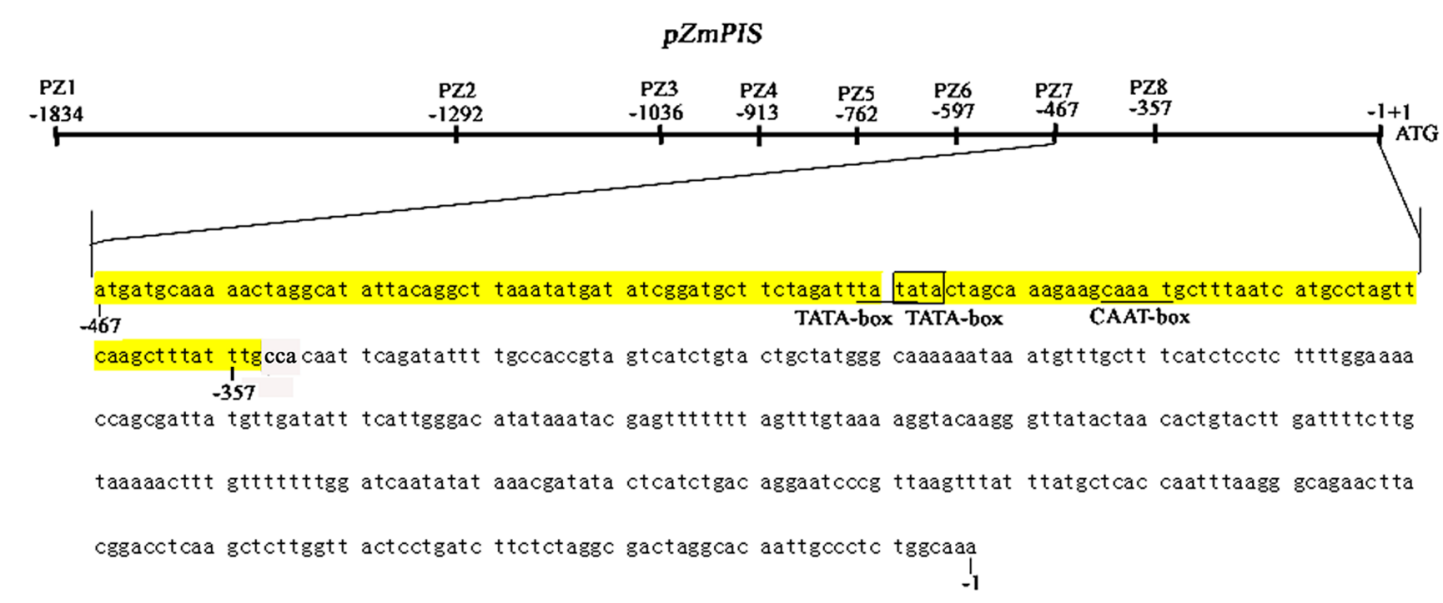

FIGURE 8 | The diagram of 467 bp (-467 to -1 bp) core promoter segment (PZ7) and 113 bp ( -467 to -355 bp) key region for responding to salinity and osmotic stress of ZmPIS. Known cis-acting elements in the 113 bp region of pZmPIS using the PlantCARE and PLACE databases are shown in underline or border. TATA-box: core promoter element around -30 of transcription start. CAAT-box: common cis-acting element in promoter and enhancer regions.

(PZ7) core fragment of ZmPIS promoter by $5^{\prime}$ deleted mutant analysis. The transcription activity of PZ7 was the highest in all tissues of transgenic tobacco among PZ1-PZ8, which corresponds to about 20 and $50 \%$ of CaMV35S promoter under normal and salt/osmotic stress conditions, respectively. The results imply that $\mathrm{PZ7}$ has high transcriptional activity, especially under salt/osmotic stress. It is known that strong expression of transgenes in plants might be also harmful for the growth and development, probably resulting in excessive waste of energy or plant morphological and physiological dysfunction (Potenza et al., 2004; Zhou et al., 2013; Han et al., 2015). In contrast with CaMV35S, the PZ7 might be useful for moderate transgene expression and more importantly enables the expression of transgenes at desired levels under adverse environment conditions such as salinity or osmotic stress. In addition, the size of PZ7 fragment is only $467 \mathrm{bp}$. The small plantderived inducible promoters are useful for avoiding the repetitive usage of the constitutive promoter and reducing the vector size and thereby beneficial for genetic transformation (Han et al., 2015).

With the continuous progress of transgenic research in plants, the precise expression of exogenous genes in the host plants is increasingly required. It has been known that multiple transgenes are introduced into plants and regulated expression by the same promoter in the vector which may result in homology dependent gene silencing (Matzke and Matzke, 1995; Verdaguer et al., 1996; De Wilde et al., 2000; Han et al., 2015). Utilizing heterologous promoters to regulate the expression of target genes in transgenic receptors facilitates the prevention of gene silencing resulting from homologous promoter sequences (Kumpatla et al., 1998; Dong et al., 2015). In the study, we used heterologous promoters from maize to regulate GUS expression in tobacco and identified a 467 bp fragment (PZ7) that confers highlevel and stress inducible gene expression in transgenic tobacco plants. This promoter fragment of $Z m P I S$ from monocot will be useful for salt- or drought- resistance breeding in dicot crops.
The transcriptional activity and expression pattern of promoters derived from different sources may also have obvious difference in dicot and monocot. In monocots, ubiquitin promoters are generally more capable of driving transgene expression than the CaMV35S (Christensen et al., 1992; Cornejo et al., 1993; Schledzewski and Mendel, 1994; Joung and Kamo, 2006; Kamo et al., 2012; Tao et al., 2015). Some ubiquitin promoter derived from monocots fails to direct transgene expression in dicot. The Ubil promoter showed less than $10 \%$ the transcriptional activity of CaMV35S in tobacco protoplasts (Schledzewski and Mendel, 1994). However, some promoters display strong transcriptional activity generally in both dicot and monocot. For example, a $0.3 \mathrm{~kb}$ AtCTTP promoter shows high transcriptional activity in Arabidopsis (dicot) and creeping bentgrass (monocot), implying that the small promoter can be used in both dicot and monocot plant transformation (Han et al., 2015). In the study, the PZ7 fragment of ZmPIS promoter derived from maize (monocot) displays strong transcriptional activity in tobacco (dicot), especially under salt or osmotic stress. Further characterization of transcriptional activity and expression patterns of PZ7 promoter in maize and evaluation of its application prospect in genetic improvement of monocot crops will also be meaningful.

In Summary, the $p Z m P I S$ promoter integrates multiple signal pathways that regulate plant developmental processes and allow plants to cope with multiple environments. A series of known cisacting elements that enables the induced expression of ZmPIS by multiple abiotic stresses and hormones were present in its promoter sequence, but no salinity or osmotic stress related cis-regulatory element was found. In the present study, our results indicated that $p Z m P I S$ could well respond to $\mathrm{NaCl}$ or PEG stimulation by GUS histochemical staining and fluorometric assay. A 113 bp segment ( -467 to -355 bp) be identified as key region for the response to salinity/osmotic stress by 5 ' deleted mutation analysis of pZmPIS (Figure 8), which are useful for the future studies on ZmPIS interactions with other proteins involved in salt or osmotic stress signaling pathways. 
Furthermore, a 467 bp ( -467 to -1 bp) fragment upstream from the transcription start site of $Z m P I S$ could drive transgene high-level expression in an inducible manner in tobacco leaves and may be utilized as a novel salinity or osmotic stress inducible promoter system in the development of transgenic plants (Figure 8). Abiotic stress adaptability in crop is a complex trait, and single transgene introduction may not be sufficient to improve crop stress tolerance under natural conditions. To express multiple trangsgenes in an inducible manner will help to improve the adaptability of crops to adversity. The small PZ7 promoter could be of great use to drive transgenes expression at desired levels based on its promoter activity and inducibility.

\section{AUTHOR CONTRIBUTIONS}

$\mathrm{HZ}, \mathrm{JH}$, and $\mathrm{PJ}$ performed the isolation and functional analysis of promoter $p Z m P I S$; SQ participated in data analysis; CX and QH

\section{REFERENCES}

Agarwal, P. K., Shukla, P. S., Gupta, K., and Jha, B. (2013). Bioengineering for salinity tolerance in plants: state of the art. Mol. Biotechnol. 54, 102-123. doi: 10.1007/s12033-012-9538-3

Bradford, M. M. (1976). A rapid and sensitive method for the quantitation of microgram quantities of protein utilizing the principle of proteindye binding. Ann. Biochem. 72, 248-254. doi: 10.1016/0003-2697(76)90 527-3

Cheon, B. Y., Kim, H. J., Oh, K. H., Bahn, S. C., Ahn, J. H., Choi, J. W., et al. (2004). Overexpression of human erythropoietin (EPO) affects plant morphologies: retarded vegetative growth in tobacco and male sterility in tobacco and Arabidopsis. Transgenic Res. 13, 541-549. doi: 10.1007/s11248-004-2737-3

Christensen, A. H., Sharrock, R. A., and Quail, P. H. (1992). Maize polyubiquitin genes: structure, thermal perturbation of expression and transcript splicing, and promoter activity following transfer to protoplasts by electroporation. Plant Mol. Biol. 18, 675-689. doi: 10.1007/BF00020010

Cornejo, M. J., Luth, D., Blankenship, K. M., Anderson, O. D., and Blechl, A. E. (1993). Activity of a maize ubiquitin promoter in transgenic rice. Plant Mol. Biol. 23, 567-581. doi: 10.1007/BF00019304

Das, S., Hussain, A., Bock, C., Keller, W. A., and Georges, F. (2005). Cloning of Brassica napus phospholipase C2 (BnPLC2), phosphatidylinositol 3-kinase (BnVPS34) and phosphatidylinositol synthase1 (BnPtdIns S1) - comparative analysis of the effect of abiotic stresses on the expression of phosphatidylinositol signal transduction-related genes in B. napus. Planta 220, 777-784. doi: 10.1007/s00425-004-1389-0

De Wilde, C., Van Houdt, H., De Buck, S., Angenon, G., De Jaeger, G., and Depicker, A. (2000). Plants as bioreactors for protein production: avoiding the problem of transgene silencing. Plant Mol. Biol. 43, 347-359. doi: 10.1007/97894-011-4183-3_16

Dong, Q., Jiang, H., Xu, Q., Li, X., Peng, X., Yu, H., et al. (2015). Cloning and characterization of a multifunctional promoter from Maize (Zea mays L.). Appl. Biochem. Biotechnol. 175, 1344-1357. doi: 10.1007/s12010-014-1277-4

Golldack, D., Li, C., Mohan, H., and Probst, N. (2014). Tolerance to drought and salt stress in plants: unraveling the signaling networks. Front. Plant Sci. 5:151. doi: 10.3389/fpls.2014.00151

Han, Y. J., Kim, Y. M., Hwang, O. J., and Kim, J. I. (2015). Characterization of a small constitutive promoter from Arabidopsis translationally controlled tumor protein (AtTCTP) gene for plant transformation. Plant Cell Rep. 34, 265-275. doi: 10.1007/s00299-014-1705-5

Heilmann, I. (2009). Using genetic tools to understand plant phosphoinositide signaling. Trends Plant Sci. 14, 171-179. doi: 10.1016/j.tplants

Higo, K., Ugawa, Y., Iwamoto, M., and Korenaga, T. (1999). Plant cis-acting regulatory DNA elements (PLACE) database. Nucleic Acids Res. 27, 297-300. doi: 10.1093/nar/27.1.297 critically revised the manuscript; $\mathrm{ZD}, \mathrm{ZW}$, and $\mathrm{KZ}$ participated in experimental design and manuscript proof reading; $\mathrm{KL}$ conceived and designed research, and drafted the manuscript. All authors read and approved the manuscript.

\section{FUNDING}

This work was supported by grants from the National Program of Transgenic Variety Development of China (2014ZX0800922B) and State Key Laboratory of Crop Biology (2015KF03).

\section{SUPPLEMENTARY MATERIAL}

The Supplementary Material for this article can be found online at: http://journal.frontiersin.org/article/10.3389/fpls.2016.00042

Jefferson, R. A., Kavanagh, T. A., and Bevan, M. W. (1987). GUS fusions: betaglucuronidase as a sensitive and versatile gene fusion marker in higher plants. EMBO J. 6, 3901-3907

Joung, Y. H., and Kamo, K. (2006). Expression of a polyubiquitin promoter isolated from Gladiolus. Plant Cell Rep. 25, 1081-1088. doi: 10.1007/s00299-006-0185-7

Kamo, K., Kim, A. Y., Park, S. H., and Joung, Y. H. (2012). The 5' UTR-intron of the Gladiolus polyubiquitin promoter GUBQ1 enhances translation efficiency in Gladiolus and Arabidopsis. BMC Plant Biol. 12:79. doi: 10.1186/14712229-12-79

Kaur, C., Kumar, G., Kaur, S., Ansari, M. W., Pareek, A., Sopory, S. K., et al. (2015). Molecular cloning and characterization of salt overly sensitive gene promoter from Brassica juncea (BjSOS2). Mol. Biol. Rep. 42, 1139-1148. doi: 10.1007/s11033-015-3851-4

Koia, J., Moyle, R., Hendry, C., Lim, L., and Botella, J. R. (2013). Pineapple translation factor SUI1 and ribosomal protein L36 promoters drive constitutive transgene expression patterns in Arabidopsis thaliana. Plant Mol. Biol. 81, 327-336. doi: 10.1007/s11103-012-0002-3

König, S., Mosblech, A., and Heilmann, I. (2007). Stress-inducible and constitutive phosphoinositide pools have distinctive fatty acid patterns in Arabidopsis thaliana. FASEB J. 21, 1958-1967. doi: 10.1096/fj.06-7887com

Kumpatla, S. P., Chandrasekharan, M. B., and Lyer, L. M. (1998). Genome intruder scanning and modulation systems and transgene silencing. Trends Plant Sci. 3, 96-104. doi: 10.1016/S1360-1385(97)01194-1

Lescot, M., Déhais, P., Thijs, G., Marchal, K., Moreau, Y., Van de Peer, Y., et al. (2002). PlantCARE, a database of plant cis-acting regulatory elements and a portal to tools for in silico analysis of promoter sequences. Nucleic Acids Res. 30, 325-327. doi: 10.1093/nar/30.1.325

Lin, W. H., Ye, R., Ma, H., Xu, Z. H., and Xue, H. W. (2004). DNA chip-based expression profile analysis indicates involvement of the phosphatidylinositol signaling pathway in multiple plant responses to hormone and abiotic treatments. Cell Res. 14, 34-45. doi 10.1038/sj.cr.7290200

Liu, X., Zhai, S., Zhao, Y., Sun, B., Liu, C., Yang, A., et al. (2013). Overexpression of the phosphatidylinositol synthase gene (ZmPIS) conferring drought stress tolerance by altering membrane lipid composition and increasing ABA synthesis in maize. Plant Cell Environ. 36, 1037-1055. doi: 10.1111/pce.12040

Löfke, C., Ischebeck, T., König, S., Freitag, S., and Heilmann, I. (2008). Alternative metabolic fates of phosphatidylinositol produced by phosphatidylinositol synthase isoforms in Arabidopsis thaliana. Biochem. J. 413, 115-124. doi: 10.1042/BJ20071371

Matzke, M. A., and Matzke, A. J. (1995). Homology-dependent gene silencing in transgenic plants: what does it really tell us? Trends Genet. 11, 1-3. doi: 10.1016/S0168-9525(00)88973-8

Munnik, T., and Vermeer, J. E. M. (2010). Osmotic stress-induced phosphoinositide and inositol phosphate signalling in plants. Plant Cell Environ. 33, 655-669. doi: 10.1111/j.1365-3040.2009.02097.x 
Munns, R., and Tester, M. (2008). Mechanisms of salinity tolerance. Annu. Rev. Plant Biol. 59, 651-681. doi: 10.1146/annurev.arplant.59.032607.092911

Odell, J. T., Nagy, F., and Chua, N. H. (1985). Identification of DNA sequences required for activity of the cauliflower mosaic virus $35 \mathrm{~S}$ promoter. Nature 313 , 810-812. doi: 10.1038/313810a0

Pan, Y., Ma, X., Liang, H., Zhao, Q., Zhu, D., and Yu, J. (2015). Spatial and temporal activity of the foxtail millet (Setaria italica) seed-specific promoter pF128. Planta 241, 57-67. doi: 10.1007/s00425-014-2164-5

Perera, I. Y., Hung, C. Y., Moore, C. D., Stevenson-Paulik, J., and Boss, W. F. (2008). Transgenic Arabidopsis plants expressing the type 1 inositol 5-phosphatase exhibit increased drought tolerance and altered abscisic acid signaling. Plant Cell 20, 2876-2893. doi: 10.1105/tpc.108.061374

Potenza, C., Aleman, L., and Sengupta-Gopalan, C. (2004). Targeting transgene expression in research, agricultural, and environmental applications: promoters used in plant transformation. In Vitro Cell Dev. Biol. 40, 1-22. doi: 10.1079/IVP2003477

Rai, M., He, C., and Wu, R. (2009). Comparative functional analysis of three abiotic stress-inducible promoters in transgenic rice. Transgenic Res. 18, 787-799. doi: 10.1007/s11248-009-9263-2

Schledzewski, K., and Mendel, R. R. (1994). Quantitative transient gene expression: comparison of the promoters for maize polyubiquitin1, rice actin1, maizederived Emu and CaMV 35S in cells of barley, maize and tobacco. Transgenic Res. 3, 249-255. doi: 10.1007/BF02336778

Shinozaki, Y., and Shinozaki, K. (1993). Characterization of the expression of a desiccation-responsive rd29 gene of Arabidopsis thaliana and analysis of its promoter in transgenic plants. Mol. Gen. Genet. 236, 331-340. doi: $10.1007 / \mathrm{BF} 00277130$

Sinha, N. R., Williams, R. E., and Hake, S. (1993). Overexpression of the maize homeo box gene, KNOTTED-I, causes a switch from determinate to indeterminate cell fates. Gene Dev. 7, 787-795. doi: 10.1101/gad.7.5.787

Sui, Z., Niu, L., Yue, G., Yang, A., and Zhang, J. (2008). Cloning and expression analysis of some genes involved in the phosphoinositide and phospholipid signaling pathways from maize (Zea mays L.). Gene 426, 47-56. doi: 10.1016/j.gene.2008.09.004

Sun, Q. H., Gao, F., Zhao, L., Li, K. P., and Zhang, J. R. (2010). Identification of a new $130 \mathrm{bp}$ cis-acting element in the TsVP1 promoter involved in the salt stress response from Thellungiella halophila. BMC Plant Biol. 10:90. doi: 10.1186/1471-2229-10-90

Tao, Y. B., He, L. L., Niu, L. J., and Xu, Z. F. (2015). Isolation and characterization of an ubiquitin extension protein gene (JcUEP) promoter from Jatropha curcas. Planta 241, 823-836. doi: 10.1007/s00425-014-2222-z

Tavakol, E., Sardaro, M. L., Shariati, J. V., Rossini, L., and Porceddu, E. (2014). promoter analysis and expression profile of in response to drought stress in wheat ancestors. Gene 549, 24-32. doi: 10.1016/j.gene.2014.07.020

Tester, M., and Langridge, P. (2010). Breeding technologies to increase crop production in a changing world. Science 327, 818-822. doi: 10.1126/science. 1183700

Verdaguer, B., de Kochko, A., Beachy, R. N., and Fauquet, C. (1996). Isolation and expression in transgenic tobacco and rice plants, of the cassava vein mosaic virus (CVMV) promoter. Plant Mol. Biol. 31, 1129-1139. doi: 10.1007/BF00040830

Voelker, T., Sturm, A., and Chrispeels, M. J. (1987). Differences in expression between two seed lectin alleles obtained from normal and lectin deficient beans are maintained in transgenic tobacco. EMBO J. 6, 3571-3577.

Wang, X. (2004). Lipid signaling. Curr. Opin. Plant Biol. 7, 329-336. doi: 10.1016/j.pbi.2004.03.012

Welti, R., Li, W., Li, M., Sang, Y., Biesiada, H., Zhou, H. E., et al. (2002). Profiling membrane lipids in plant stress responses. Role of phospholipase D alpha in freezing-induced lipid changes in Arabidopsis. J. Biol. Chem. 277, 31994-32002. doi: 10.1074/jbc.M205375200

Xue, H. W., Chen, X., and Mei, Y. (2009). function and regulation of phospholipid signalling in plants. Biochem. J. 421, 145-156. doi: 10.1042/BJ20090300

Xue, H. W., Xu, C. Z., and Li, G. (2007). Involvement of phospholipid signaling in plant growth and hormone effects. Curr. Opin. Plant Biol. 10, 483-489. doi: 10.1016/j.pbi.2007.07.003

Yang, Y., Li, R., and Qi, M. (2000). In vivo analysis of plant promoters and transcription factors by agroinfiltration of tobacco leaves. Plant J. 22, 543-551. doi: 10.1046/j.1365-313x.2000.00760.x

Zavallo, D., Bilbao, M. L., Hopp, H. E., and Heinz, R. (2010). Isolation and functional characterization of two novel seed-specific promoters from sunflower (Helianthus annuus L.). Plant Cell Rep. 29, 239-248. doi: 10.1007/s00299-010-0816-X

Zhai, S. M., Gao, Q., Xue, H. W., Sui, Z. H., Yue, G. D., Yang, A. F., et al. (2012). Overexpression of the phosphatidylinositol synthase gene from Zea mays in tobacco plants alters the membrane lipids composition and improves drought stress tolerance. Planta 235, 69-84. doi: 10.1007/s00425-011-1490-0

Zhang, Y., Yin, H., Li, D., Zhu, W., and Li, Q. (2008). Functional analysis of BADH gene promoter from Suaeda liaotungensis K. Plant Cell Rep. 27, 585-592. doi: 10.1007/s00299-007-0459-8

Zhao, J., Ren, W., Zhi, D., Wang, L., and Xia, G. (2007). Arabidopsis DREB1A/CBF3 bestowed transgenic tall fescue increased tolerance to drought stress. Plant Cell Rep. 26, 1521-1528. doi: 10.1007/s00299-0070362-3

Zhou, J., Yang, Y., Wang, X., Yu, F., Yu, C., Chen, J., et al. (2013). Enhanced transgene expression in rice following selection controlled by weak promoters. BMC Biotechnol. 13:29. doi: 10.1186/1472-6750-13-29

Conflict of Interest Statement: The authors declare that the research was conducted in the absence of any commercial or financial relationships that could be construed as a potential conflict of interest.

Copyright (c) 2016 Zhang, Hou, Jiang, Qi, Xu, He, Ding, Wang, Zhang and Li. This is an open-access article distributed under the terms of the Creative Commons Attribution License (CC BY). The use, distribution or reproduction in other forums is permitted, provided the original author(s) or licensor are credited and that the original publication in this journal is cited, in accordance with accepted academic practice. No use, distribution or reproduction is permitted which does not comply with these terms. 